\title{
Overlooked health priorities as Liberals form new government
}

Cite as: CMAJ 2021 October 18:193:E1603-4. doi: 10.1503/cmaj.1095964

Posted on cmajnews.com on October 1, 2021

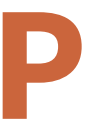

andemic preparedness and recovery may have dominated the federal election campaign, but health advocates and policy experts say other pressing health issues also demand attention from the incoming Liberal government.

Re-elected Prime Minister Justin Trudeau campaigned to curb COVID-19 by mandating vaccinations for travellers and federal workers, ensuring free access to booster shots, and investing $\$ 180$ million in ventilation projects and $\$ 100$ million to study long COVID.

In other commitments, the Liberals pledged to establish a new mental health funding transfer to the provinces, hire 7500 new doctors and nurses and increase debt relief for rural health professionals, and invest $\$ 3$ billion to improve long-term care and $\$ 4$ billion to help eliminate health system wait lists.

Canadian Medical Association (CMA) President Dr. Katharine Smart welcomed the Liberal Party's promises to support vaccine passports and set national standards for long-term care. In the case of long-term care, Smart says chronic underfunding has contributed to a system that's "barely working" under pandemic pressures.

\section{Health human resources}

When it comes to health worker shortages, however, Smart says federal action must go beyond hiring more people to strengthening health human resources planning.

She says that includes developing a national health workforce plan and data infrastructure to know "where people are actually needed," while supporting health worker well-being.

The CMA is also calling for the panCanadian licensure of medical practitioners so that physicians across the country can mobilize quickly to provide backup during emergencies.

Meanwhile, the Canadian Nurses Association (CNA) wants the federal government to establish a dedicated national coordinating body to address health workforce gaps. And given that pandemic burnout is contributing to nurses leaving the profession, CNA wants the government to develop strategies for providing "tailored, sustainable, accessible, long-term mental health supports for health workers."

\section{Anti-racist action}

Both the CMA and CNA are pushing for federal action to address the health impacts of racism - an issue some experts say fell to the wayside during the election campaign.

Last year, Indigenous health advocates called on the former Liberal government to adopt anti-racism as the sixth pillar of the Canada Health Act.

"There was a lot of attention around systemic racism in health care and the experiences of Black folks, Indigenous people, and other racialized people," says Michael Orsini, a professor of health policy at the University of Ottawa. "That seems to have been all but forgotten [on the campaign trail]."

With a new Parliament, Orsini says, "there is an opportunity to speak more meaningfully about health policy reform that would seriously address systemic racism."

The Liberals have committed to upholding Indigenous Peoples' "equal right to the highest standard of physical and mental health," known as Joyce's Principle - named after Joyce Echaquan, an Atikamekw woman who filmed health workers mocking her not long before she died in hospital last year.
Canada has a long way to go toward reconciliation, especially considering that many Indigenous communities still don't have safe drinking water, Orsini says.

The CNA is calling on the federal government to immediately provide reliable, permanent access to high-quality drinking water in all Indigenous communities. They also want the government to intensify cultural safety training for non-Indigenous health workers and fund the recruitment, advancement, and retention of people of colour in health care.

Meanwhile, the Canadian Health Coalition says front-line health workers from marginalized groups "must be included in efforts to eliminate systemic racism and other barriers to care."

\section{Expanding Medicare}

The COVID-19 pandemic has underscored links between poverty and health disparities, but also the feasibility of a national basic income scheme to close those gaps, says Orsini.

Yet, despite the success of the former Liberal government's Canadian Emergency Response Benefit, only the New Democratic Party has pledged support for a permanent scheme.

Researchers from the University of Calgary have studied the health impacts of a guaranteed annual income program using seniors' benefits as an example.

They found that people receiving a guaranteed annual income had better physical and mental health outcomes than those receiving conditional income assistance - a health boost that lasted at least a decade.

"These improvements [in health outcomes] are likely to yield reduced health care costs, which may offset the costs [of a 
basic income program]," according to the authors.

Expanding coverage of prescription drugs under Medicare is another way the government could tackle health disparities related to poverty. Prior to the pandemic, one in four Canadian households struggled to afford their medications.

The Liberals campaigned in 2019 to "take the critical next steps to implement national universal pharmacare." However, their 2021 budget and platform contained no new commitments to that end.

The Canadian Health Coalition would see the new government finally implement universal and public drug coverage "just as essential vaccines have been provided free of charge."

Meanwhile, the Canadian Paediatric Society is calling for a national pediatricsensitive formulary and compounding registry to inform funding and prescribing of medicines for children.

\section{Climate change}

With just a decade to limit global warming to $1.5^{\circ} \mathrm{C}$ above preindustrial levels, the new federal government also has a pivotal role to play in averting the worst impacts of climate change.

When Canada first signed the Paris agreement in 2005, the federal government committed to cutting greenhouse gas emissions to $30 \%$ by 2030 . Earlier this year, the Liberals raised that target to $40 \%-45 \%$. However, the party's climate plan doesn't address the emergency as a public health crisis.

The CMA and the Canadian Association of Physicians for the Environment (CAPE) are both calling on the federal government to address the growing health impacts of the crisis.

According to CAPE, "the COVID-19 pandemic did not replace the other environmental health concerns we are facing - if anything, it has brought into focus the interconnectedness of human health and our environments."

CAPE is urging the incoming government to modernize the Canadian Environmental Protection Act, phase out fossil fuels entirely and end exports of coal to be burned for electricity.

According to executive director Dr. Anjali Helferty, "What is missing across the board in relation to the climate emergency is a response that is appropriate to the scale and risk of the current and future crises we face."

\section{Diana Duong and Lauren Vogel, CMAJ}

Content licence: This is an Open Access article distributed in accordance with the terms of the Creative Commons Attribution (CC BY-NC-ND 4.0) licence, which permits use, distribution and reproduction in any medium, provided that the original publication is properly cited, the use is noncommercial (i.e., research or educational use), and no modifications or adaptations are made. See: https://creativecommons.org/ licenses/by-nc-nd/4.0/ 